\title{
Ozone reduces crop yields and alters competition with weeds such as yellow nutsedge
}

\author{
David A. Grantz \\ Anil Shrestha \\ $\nabla$
}

In recent decades, air quality has improved near most cities but not in rural areas such as the San Joaquin Valley. Many studies using diverse exposure techniques have shown that ground-level ozone air pollution reduces plant growth and yield, from negligible impacts in some species to over $30 \%$ losses in others. We studied the interaction of ozone with weed competition from yellow nutsedge in Pima cotton and tomato in opentop field-exposure chambers at the UC Kearney Research and Extension Center in Fresno County. Ozone impacts on cotton (which is relatively sensitive) were compounded by weed competition, whereas tomato (which is less sensitive) competed well at all ozone concentrations. Our data suggests that crop-loss estimates obtained in single-factor experiments accurately reflect the serious risk of ozone to agriculture, but that more accurate yield predictions will require the consideration of interactions between the components of complex crop production systems, including weed competition.

$\square$ he economic viability of crop pro1 duction in the San Joaquin Valley is threatened in many ways. Chronic threats include reduced crop vigor caused by competition from newly introduced weeds, some of which are increasingly difficult to control, and damage caused by the changing global climate, including increased groundlevel ozone (Fuhrer 2003). Ozone can be either "good" or "bad," depending on where it is in the atmosphere. Ozone in the upper atmosphere between 10 to 30 miles ( 15 to 50 kilometers; the stratosphere) is naturally occurring and
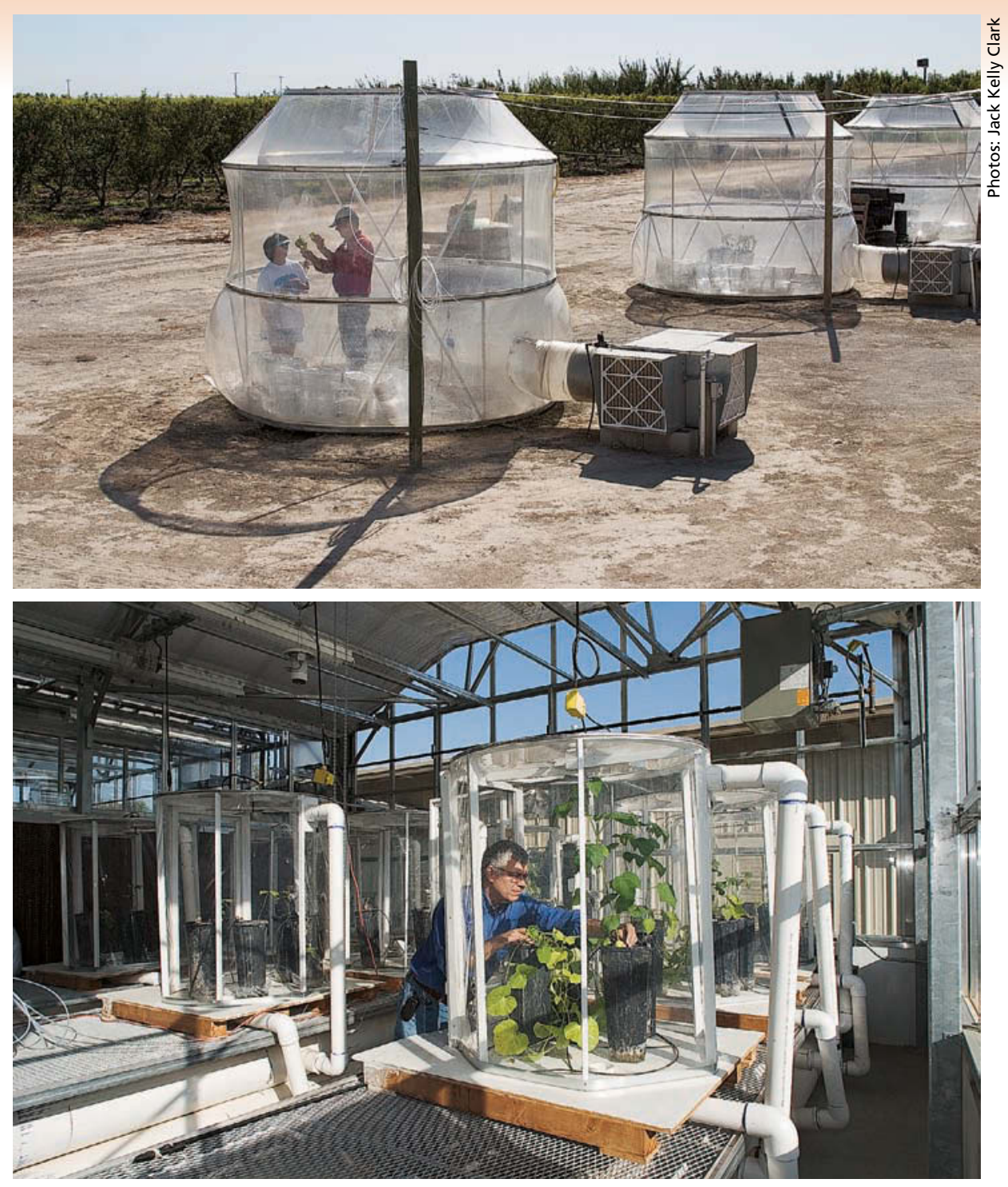

Top, Kearney-based air pollution effects specialist David Grantz (right) and technician Margo Toyota (left) evaluate ozone impacts on cotton in an open-top chamber (OTC) at Kearney. At current ozone concentrations in the San Joaquin Valley, yields can decline up to one third depending on the crop. Bottom, Grantz checks cotton plants growing in a closed chamber in Kearney's new state-of-the-art greenhouse.

"good," in that it absorbs ultraviolet light, protecting against sunburn, skin cancer and damage to vegetation and sensitive aquatic species.

In contrast, ozone produced at ground level and mixed into the air, up to about 6 to 12 miles (10 to 20 kilometers; the troposphere), is mostly attributable to human activity and is considered "bad." It is a strong oxidant in the environment, injuring human lungs, crops and native plants, and materials such as stone, paint and plastics. This groundlevel ozone, or smog, inhibits lung development in children, induces asthma attacks and has been linked to increased hospital admissions and deaths.

Ground-level ozone is derived from emissions of oxides of nitrogen (from high-temperature combustion including automobiles, power plants and factory boilers) and emissions of volatile organic compounds (evaporating gasoline, paints and solvents, pesticides 


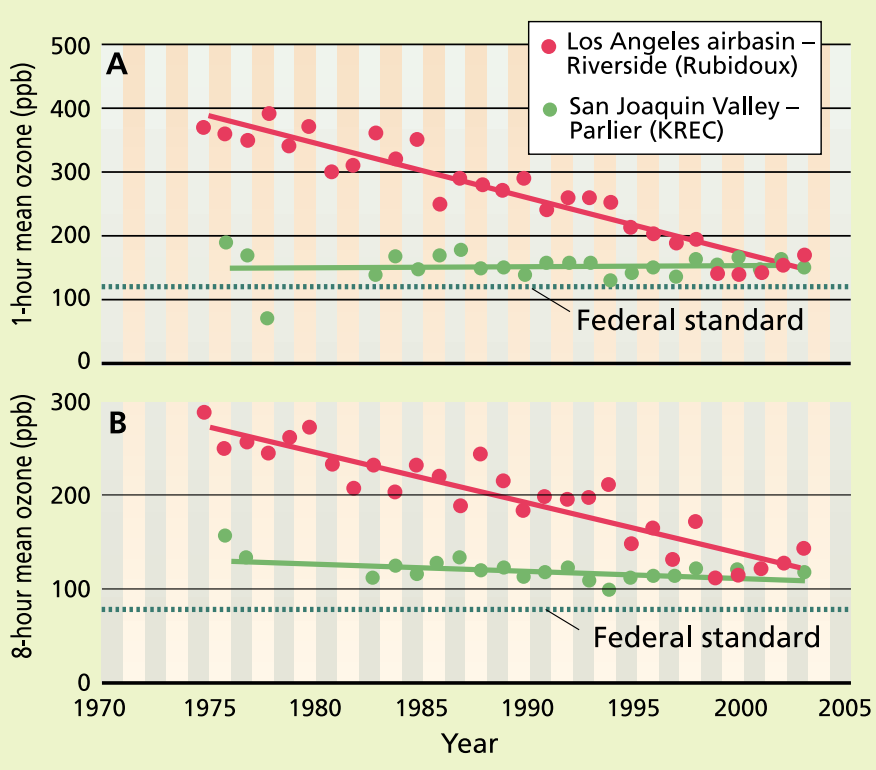

Fig. 1. Trends of ozone air quality in the (A) Los Angeles and (B) San Joaquin Valley air basins. The high concentrations observed in the 1970s in the Los Angeles air basin are no longer observed; the San Joaquin Valley and Los Angeles basins recently traded places as having the worst air in the United States.

and plant products including fragrant compounds). Natural background concentrations of ground-level ozone are about 20 to 25 parts per billion by volume (ppb). As concentrations increase above this level they become increasingly harmful to human health. The California health-based 1-hour standard is $90 \mathrm{ppb}$ (fig.1A) and the federal standard is $120 \mathrm{ppb}$ (fig.1B), although both standards may be too high to be protective. Crops are damaged above concentrations of 40 to $60 \mathrm{ppb}$.

Ground-level ozone is a long-standing and worsening problem in many rural areas. Curiously, while rural air quality has not improved rapidly, air quality in Los Angeles and other major metropoli$\tan$ areas has. This difference is due to rapid population growth in affordable rural areas such as the Central Valley, and the initial abundance in urban areas of easily identifiable air pollution sources such as factories and industrial processes. The steep decline in ozone concentrations at the Rubidoux monitoring site in Riverside County, in the South Coast (Los Angeles) air basin, contrasts dramatically with the nearly flat trend at the Parlier monitoring site at the UC Kearney Research and Extension Center (KREC) in the San Joaquin Valley air basin (fig. 1). Similar trends are observed for the 1-hour average ozone concentration (the basis of the older federal air-quality standard) and for the newly established 8-hour average (the basis of the newer federal standard). However, neither region meets either standard. The San Joaquin Valley and Los Angeles air basins seem to be trading places as the most polluted regions in the United States.

San Joaquin Valley crops are grown in increasingly agroecological systems, with emphasis on integrated pest management. A critical component of these systems is crop competition with other vegetation.

Weeds cause considerable crop loss despite the extensive use of control technologies. However, weed management in the San Joaquin Valley may be further threatened by restrictions on herbicide use, due in part to air-quality concerns, and by the establishment of herbicide-resistant weeds.

\section{Ozone and crop loss}

Current ambient ozone concentrations impose substantial economic costs on producers and consumers of agricultural products in the United States (Spash 1997). Considering only ozone derived from motor vehicle
TABLE 1. Estimated statewide crop loss (\%) in California caused by ground-level ozone, 1993

\begin{tabular}{lc}
\hline Crop & \multicolumn{1}{c}{ Yield loss* } \\
\hline & $\%$ \\
Annual & \\
Lettuce & 0.5 \\
Fresh-market tomato & 0.6 \\
Field corn & 1.2 \\
Rice & 3.9 \\
Wheat & 6.7 \\
Processing tomato & 6.8 \\
Onion & 10.6 \\
Dry bean & 17.5 \\
Upland cottont & 23.3 \\
Cantaloupe & 32.8 \\
Perennial & \\
Lemon & 8.4 \\
Alfalfa & 9.5 \\
Orange & 14.0 \\
Wine grape & 22.8 \\
Raisin grape & 26.2 \\
Table grape & 29.9 \\
\hline * Statewide yield-loss data from Mutters and Soret \\
(1998), using 7-hour (27.2 ppb) and 12-hour (25 ppb) \\
mean ozone exposure crop-loss models. Losses are \\
relative to clean background air. \\
† Data is for upland cotton; comparable data for Pima \\
cotton is not available. & \\
& \\
& \\
&
\end{tabular}

emissions in the United States, about $60 \%$ of all ozone (1993 data from U.S. Environmental Protection Agency, www.epa.gov/ebtpages/air.html), and only eight major crops, the estimated economic damage due to ambient ozone in 1990 ranged from $\$ 2.8$ billion to $\$ 5.8$ billion (Murphy et al. 1999).

Despite its "big city" ozone problem, the San Joaquin Valley remains the dominant agricultural area of California. An economic cost-benefit analysis (Kim et al. 1998) suggested that controlling peak ozone concentrations to $150 \mathrm{ppb}$ in Tulare, Kings, Fresno and Madera counties would provide substantial economic benefits, even though $150 \mathrm{ppb}$ is well above the threshold (40 to $60 \mathrm{ppb}$ ) for crop damage, and peaks above $150 \mathrm{ppb}$ occur infrequently in the Valley (California Air Resources Board, www.arb.ca.gov/aqd/aqdpage.htm).

Current ambient ozone concentrations in the San Joaquin Valley can cause yield losses from nearly none to as much as a third, depending on the crop (Mutters and Soret 1998). Crop species, and even cultivars within a species, differ in both

\section{Ozone now causes economically significant losses in the yields of most crops, and this will get worse if current trends in rural population density continue.}



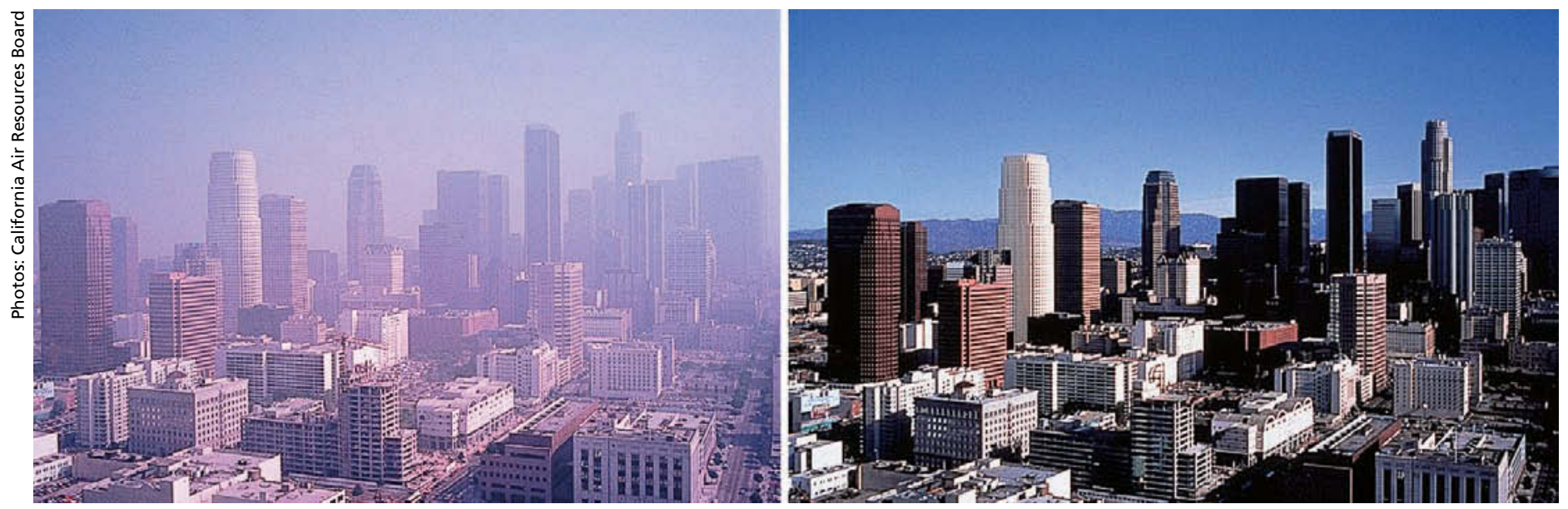

Los Angeles used to be the most polluted air basin in the United States. Left, a smoggy day in the city's downtown; right, a clear day.

sensitivity to ozone and in the ambient ozone environments in which they are grown. The two factors together determine statewide yield losses (table 1).

The equations that allow calculation of these yield losses have been derived mostly using open-top field-exposure chambers (OTCs)(Heagle et al. 1988). While OTCs may subtly alter the crop microenvironment and subsequent plant growth (Manning and Krupa 1992), they did not significantly affect crop yield in $70 \%$ of published experiments (Legge et al. 1995). In addition, crop sensitivity to ozone was generally unaffected in the few cases where direct comparisons with alternative exposure

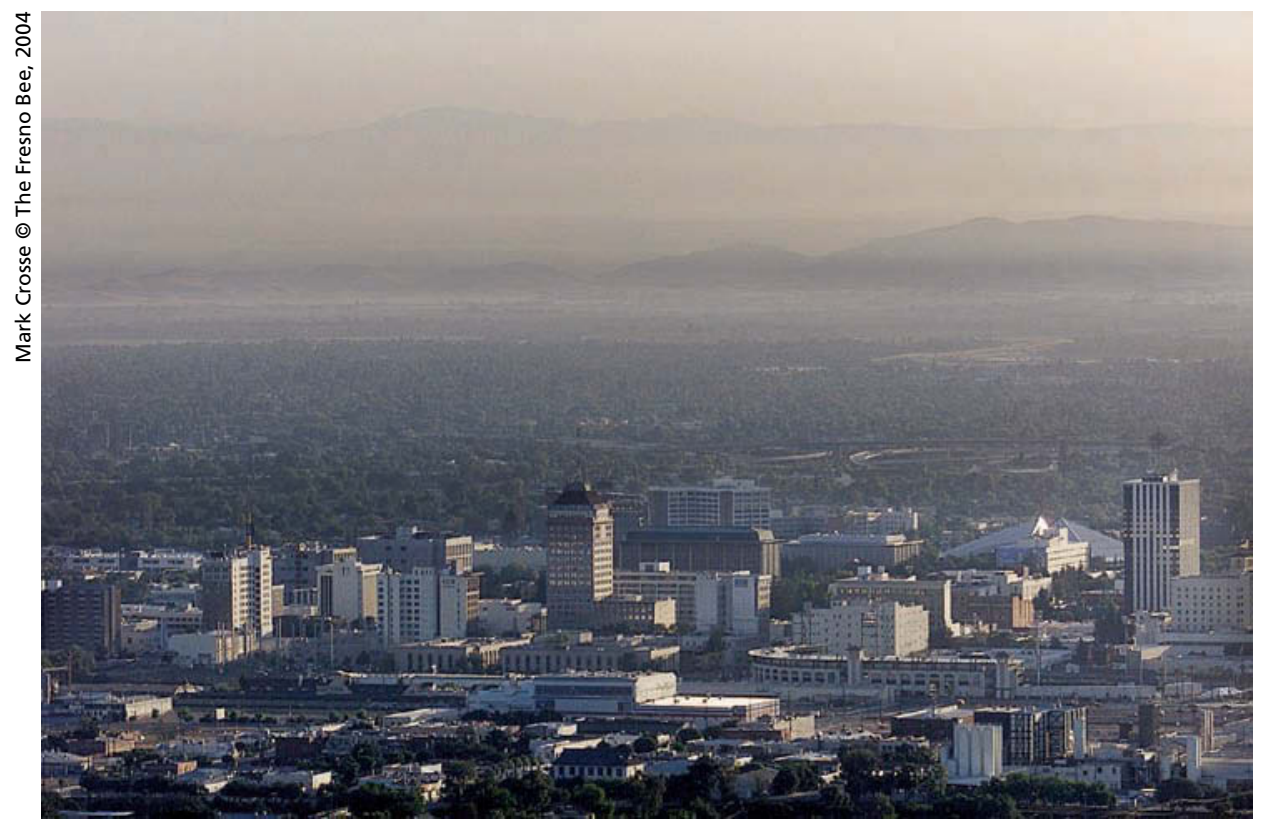

The San Joaquin Valley is now the nation's most polluted air basin. While Southern California air quality has improved remarkably in recent years, the increasing number of automobiles in the Central Valley has led to more days like this one in Fresno. methods are available (Heagle et al. 1988; Olszyk et al. 1986).

A consensus has developed among North American scientists that crops are likely to be damaged by ozone when concentrations greater than $60 \mathrm{ppb}$ exceed a total of 20,000 ppb-hours over any 90-day period (Heck and Furiness 2001). A similar consensus in Europe finds that crops are likely to be damaged by ozone when concentrations greater than $40 \mathrm{ppb}$ exceed a total of 3,000 ppb-hours (Karenlampi and Skarby 1996). These conclusions differ in magnitude due to differences in cultivars and growth environments on the two continents. However, they are similar in adopting

a threshold concentration (60 ppb or $40 \mathrm{ppb}$ ) and an accumulated exposure index (ppb-hours) as determinants of damage. There is little doubt that ozone reduces crop yields at current ambient concentrations.

Yield loss in tomato. In 2001, California produced $93 \%$ of U.S. processing tomatoes, mostly in the San Joaquin and Sacramento valleys. California's combined processing and fresh-market tomato crop is valued at approximately $\$ 766$ million (CDFA 2002). Tomato is only moderately sensitive to ozone (Temple, Surano, et al. 1985). Statewide yield losses due to ozone in 1993 (the last year available) were an estimated $6.8 \%$ for processing tomatoes and nearly none for freshmarket tomatoes (table 1).

Yield loss in cotton. In contrast, cotton is relatively sensitive to ozone (Grantz 2003). Yield reductions have been demonstrated for upland cotton cultivars (Olszyk et al. 1993; Temple, Taylor, et al. 1985), with statewide yield losses in 1993 estimated at 23.3\% (table 1). The first Pima cotton cultivars introduced into the San Joaquin Valley, including cv. S-6, were affected even more (Olszyk et al. 1993). More recent Pima cultivars - selected under ozone pressure in the San Joaquin Valley are reportedly more resistant to ozone, but confirming data is unavailable.

\section{Weed and crop competition}

Herbicides are used on much of the tomatoes (Lycopersicon esculentum Mill.) and cotton (both upland [Gossypium hirsutum L.] and Pima [G. barbadense L.]) 

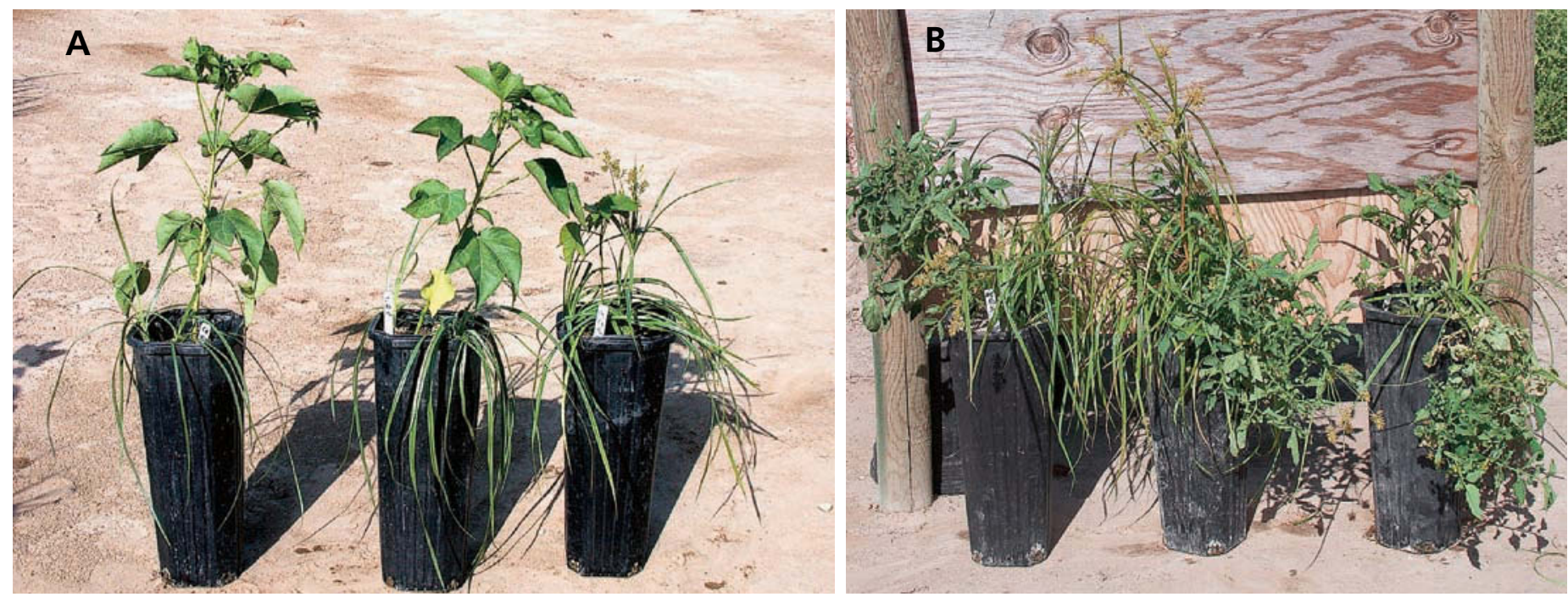

Effect of increasing ozone concentration (left to right: about 15, 80 and $150 \mathrm{ppb}$ ) on growth of (A) Pima cotton and nutsedge grown in direct competition with one nutsedge per cotton; (B) tomato and nutsedge grown in direct competition with nutsedge (two-to-one); and (C) yellow nutsedge grown in the absence of competition.

grown in California, preventing substantial crop losses (CDPR 2002). At the same time, ozone may profoundly affect these plant communities, altering the growth and fitness of both weedy and crop species as well as their competitive interactions. While ozone impacts on many important crop species have been characterized, there are few reports on the impacts of ozone on the growth and fecundity of weeds (Fuhrer and Booker 2003). Short life cycles and prolific reproduction could accelerate weed adaptation to ozone, and the enhanced competitive advantage of weeds relative to crop species could increase herbicide use. However, the impacts of ozone on such competitive systems cannot be predicted simply from the ozone sensitivities of the individual species (Evans and Ashmore 1992). It is important to consider the mechanisms of plant competition and ozone effects on interactions that may emerge only when weeds and crops are grown together.

Yellow nutsedge (Cyperus esculentus L.) has become a particularly difficult and costly weed to control in many California cropping systems. It is a $\mathrm{C}_{4}$ species, making it water efficient and heat tolerant, and thus well adapted to irrigated agriculture in the San Joaquin Valley. Because yellow nutsedge is predominantly vegetatively propagated underground by tubers, its adaptation to ozone may be slower than that of the more common sexually propagated weeds. Yellow nutsedge is well established in the San Joaquin Valley, but no data is available on this pest's response to ozone. We conducted

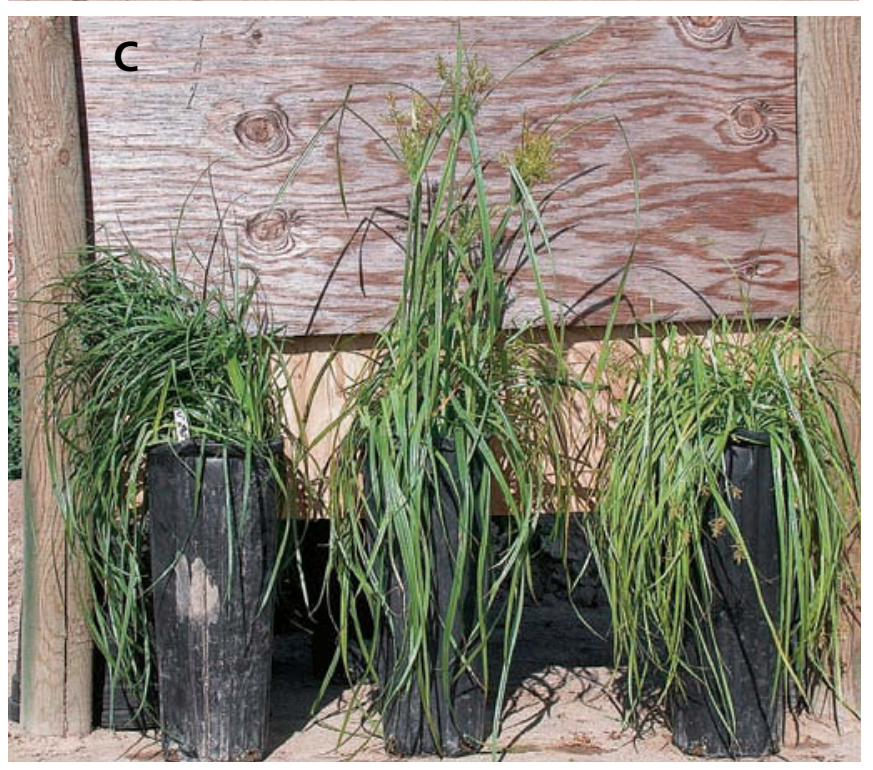

a series of experiments at KREC on the interactions of nutsedge with tomato and cotton.

\section{Exposure of plants to ozone}

Processing tomato (nursery transplants of cultivars HD 8892 and EMP 113), cotton (seeds of cv. Pima S-6) and nutsedge (locally collected juvenile plants that were about 2.5 inches [ 6 centimeters] tall with two or three leaves) were grown in outdoor OTCs during summer 2003, in 2-gallon (9-liter) pots of sintered clay ("kitty litter," 6-40 mesh), irrigated twice daily and fertilized weekly (Miracle-Gro, 0.17 ounce per gallon [1.3 grams per liter]).

Nutsedge-to-crop plant ratios in each pot were zero-to-one and one-to-zero (single species), and one-to-one, two-toone and three-to-one (competition within each pot). Three concentrations (12-hour mean exposures) of ozone were imposed: about 15 ppb (low ozone, atmospheric background), $80 \mathrm{ppb}$ (medium ozone, worst-case local ambient conditions) and $150 \mathrm{ppb}$ (high ozone).

Plants were harvested prior to flowering at 1 to 2 months after planting, separated into shoots and roots and dried at $160^{\circ} \mathrm{F}$. The root fraction in nutsedge was separated into roots (which included some rhizomes) and tubers, which were weighed separately and counted. In pots containing two species the roots were entangled, so the combined root mass was obtained.

The experiment was performed twice with tomato and once with cotton, each time with four replicate plants per treatment. The experimental design was four population ratios as subtreatments within each of the three ozone 


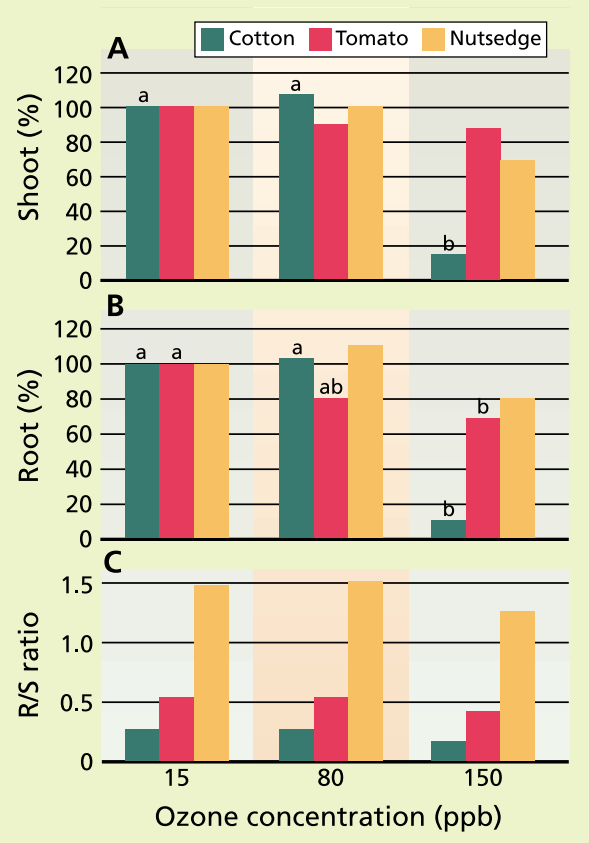

Fig. 2. Effect of increasing ozone exposure on percentage inhibition of shoot and root biomass productivity and on the resulting root-to-shoot biomass ratio (R/S) of tomato, cotton and nutsedge, grown without competition. Shoot biomass of cotton was reduced by ozone at $P=0.0007$. Root biomass of cotton and tomato were reduced by ozone at $P=0.0002$ and $P=0.0955$, respectively. R/S declined in each case but was not significant in any species.

concentrations. Species were analyzed separately. Data were transformed as required and analyzed using PROC GLM (General Linear Model; SAS). Mean separation was by Fisher's Protected LSD. Levels of significance are presented in the figure legends, and the bars in figures 2 and 3 are labeled with different letters if differences within a species are significant at $P<0.10$, a more permissive standard than the more common $P<0.05$ to accommodate the modest responses in the ozone-tolerant tomato. An additional statistical contrast was conducted between plants grown alone and with competition (averaged over all population ratios).

\section{Effects on individual species}

Cotton. As expected from our previous studies (Grantz 2003), elevated ozone negatively affected growth of the cotton plants, which were about $25 \%$ shorter and produced 50\% fewer leaves. The highest ozone concentration also reduced cotton shoot biomass by about $86 \%$ (figs. 2A, 3). In contrast, me-

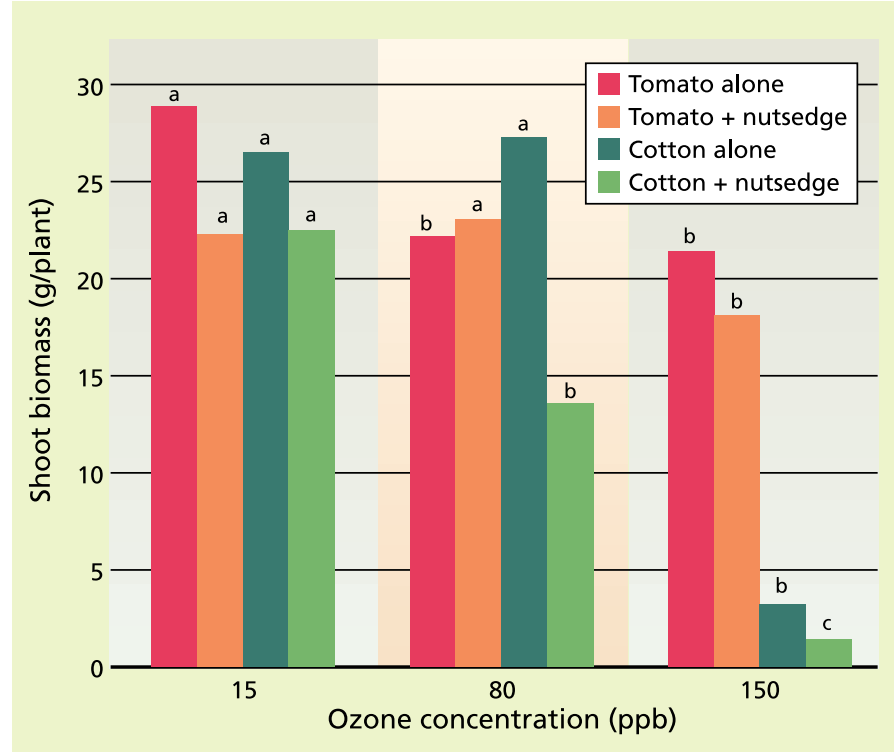

Fig. 3. Effect of ozone exposure and nutsedge competition on shoot biomass production of tomato and cotton grown alone or with nutsedge (averaged over all levels of nutsedge competition). Tomato grown alone and with nutsedge was reduced by ozone at $P=0.09$ and $P=0.08$, respectively. Cotton was far more sensitive, and was reduced by ozone at $P<0.0001$ both in the presence and absence of nutsedge.

dium ozone reduced leaf area and plant height only modestly, and in these experiments did not affect shoot biomass production (fig. 3).

The biomass of cotton roots was reduced somewhat more than that of shoots (fig. 2B), particularly at high ozone. These coordinated changes in root and shoot biomass led to a small, nonsignificant decline in the root-toshoot biomass ratio (R/S; fig. 2C). Significant declines in R/S of cotton have been observed previously at similar ozone concentrations (Grantz 2003).

Tomato. Growth was less sensitive to ozone in tomato than in cotton, particularly at the highest ozone concentration. Shoot biomass was reduced by about $19 \%$ at medium ozone with little further decrease at high ozone figs. 2A, 3). Root biomass was reduced more than shoot biomass, by about $30 \%$ at high ozone compared with low ozone (fig. 2B). The declines in tomato root and shoot biomass were sufficiently well balanced, as in cotton, that the decline in R/S was not significant (fig. 2C). Ozone has generally been found to inhibit biomass production and reduce $\mathrm{R} / \mathrm{S}$ in tomato (Varshney and Rout 1998).

Nutsedge. Increasing levels of ozone had no significant effect on either shoot biomass (figs. 2A, 3) or root biomass (fig. 2B) of nutsedge. Plants were more erect at medium than low ozone due to the presence of stiff flowering stalks, which were only occasionally observed at low or high ozone. As the ozone concentration increased further, the nutsedge leaves became more flaccid and plant height declined. Reduced plant stature has obvious implications for light interception by nutsedge in competition with crop plants. As in tomato and cotton, $\mathrm{R} / \mathrm{S}$ of nutsedge declined as expected but the change was not significant (fig. 2C).

The production and size of nutsedge tubers did not respond consistently to ozone in these experiments, and increased in many plants. Further studies are under way to determine if elevated ozone concentrations stimulate biomass allocation to the reproductive tubers, as predicted from other plant responses to abiotic stress. 

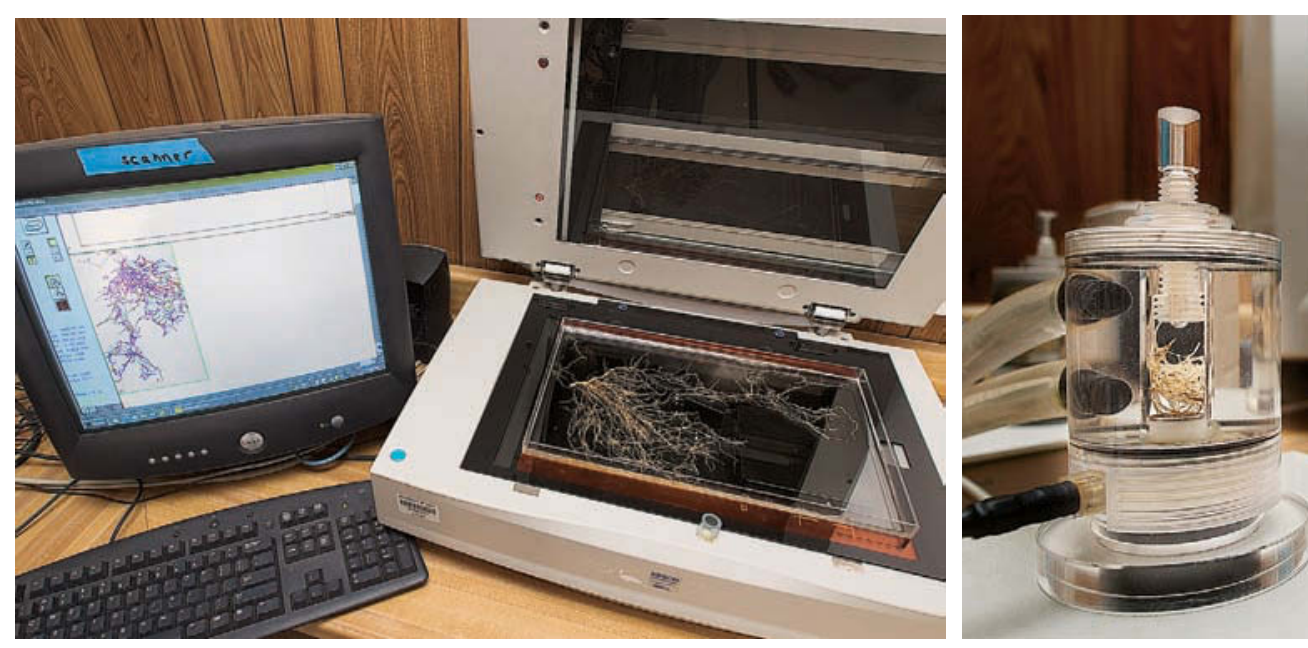

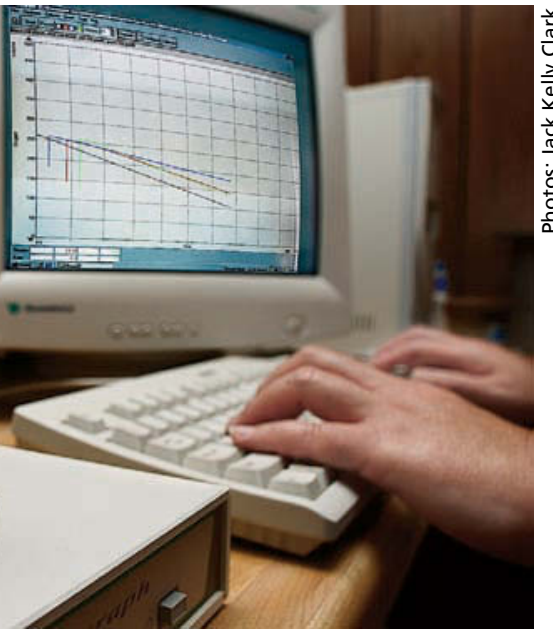

A significant but hidden aspect of ozone crop damage is reduced growth belowground, demonstrated here following exposure of plants to elevated ozone levels. Left, an intact cotton root system is scanned into a computer for an automated analysis of root length and morphology. Right, ozone causes changes in cotton root respiration, measured with a computerized oxygen electrode system. 0.096) than nutsedge root productivity was (19\% reduction; not significant) (fig. 2B). At medium ozone, tomato root biomass declined by $20 \%$ while nutsedge was unaffected.

The nutsedge shoots in the highest ozone concentration drooped over the side of the pots, further decreasing nutsedge competition for light. As observed previously for the interactions of these two species (Santos et al. 1997), tomato had a competitive advantage over nutsedge in light interception. In our studies, this advantage increased with ozone concentration. Tomato was more sensitive to ozone than nutsedge, particularly near ambient (medium) ozone, but nutsedge was more sensitive to competition than tomato.

\section{Air pollution and agriculture}

Ozone air pollution continues to be problematic in rural areas such as the San Joaquin Valley. Single-factor ozone exposure experiments have consistently indicated that ozone now causes economically significant losses in the yields of most crops, and this will get worse if current trends in rural population density continue. This conclusion is unlikely to change with further research. More complex, multifactor experiments are now required to allow more accurate estimates of current losses in specific crops, and to provide a basis for predicting losses in future presumably warmer climates. In particular, this will require consideration of the impact of ozone on the complex interactions that characterize agroecosystems, including the ozone sensitivity of crops, competing vegetation and other pest species, and on the dynamics and mechanisms of specific competitive relationships among these species. So far, this important work has only just begun. The exposure facilities recently completed in the new research greenhouse at KREC will allow us to bring further quantitative techniques to bear, particularly on the belowground competition between these crop and weed species.

In the Pima cotton-nutsedge system, cotton was more strongly affected at high ozone concentrations than nutsedge, was more inhibited by nutsedge competition, and was less able to compete with nutsedge at near ambient (80 ppb) ozone concentrations than in clean (15 ppb) air. In the tomato-nutsedge system, tomato was only moderately sensitive to ozone compared with cotton or nutsedge, competed well with nutsedge at all levels of ozone, and did not lose any competitive advantage with rising ozone concentration. Nutsedge tuber production may have increased at high ozone concentrations. This weed may become more difficult to control, spread more rapidly and require greater use of herbicides or other control strategies, particularly in ozone-sensitive crops such as Pima cot- 


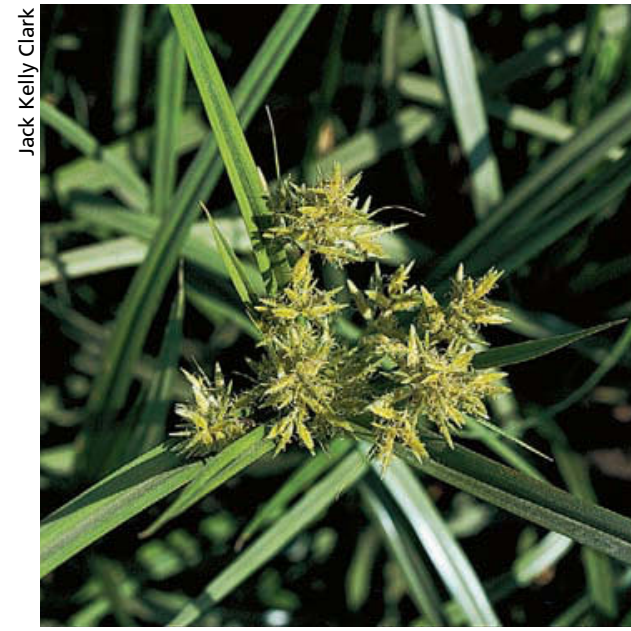

ton. These results indicate the variety of impacts that climate change, including rising ground-level ozone, may have on important crop production systems.

\section{D.A. Grantz is Director, UC Kearney Ag-} ricultural Center, and Air Pollution Effects Specialist and Plant Physiologist, Department of Botany and Plant Sciences and the Air Pollution Research Center, UC Riverside; and A. Shrestha is Integrated Pest Management Weed Ecologist, UC Statewide IPM Program. Both are located at the UC Kearney Research and Extension Center, Parlier. We gratefully acknowledge support from the USDA National Research Initiative through award 00-35100-9181.

\section{References}

[CDFA] California Department of Food and Agriculture. 2002. Resource Directory; California Agriculture: A Tradition of Innova-

\section{Yellow nutsedge may become more difficult to}

control, spreading more rapidly and requiring greater use of herbicides, particularly in ozonesensitive crops such as Pima cotton.

tion. Sacramento, CA. $180 \mathrm{p}$.

[CDPR] California Department of Pesticide Regulation. 2002. Annual Statewide Pesticide Use Report. www.cdpr.ca.gov.

Evans PA, Ashmore MR. 1992. The effects of ambient air on a semi-natural grassland community. Agric Ecosyst Environ 38:91-7.

Fuhrer J. 2003. Agroecosystem responses to combinations of elevated $\mathrm{CO}_{2}$, ozone and global climate change. Agric Ecosyst Environ 97:1-20.

Fuhrer J, Booker F. 2003. Ecological issues of ozone: Agricultural issues. Environ Intl 29:141-54.

Grantz DA. 2003. Ozone impacts on cotton: Towards an integrated mechanism. Environ Pollut 126:331-44.

Heagle AS, Kress LW, Temple PJ, et al. 1988. Factors influencing ozone dose-yield response relationships in open-top field chamber studies. In: Heck WW, Taylor OC Tingey DT (eds.). Assessment of Crop Loss from Air Pollutants: Proceedings of an International Conference; October 1987, Raleigh, NC. New York: Elsevier Appl Sci. p 141-79.

Heck WW, Furiness CS. 2001. The effects of ozone on ecological systems: Time for a full assessment. Environ Mgr (Oct):15-24.

Karenlampi L, Skarby L. 1996. Critical levels for ozone in Europe: Testing and finalizing the concepts. UN-ECE Workshop Report. Univ Kuopio, Dept Ecol Environ Sci. Kupio, Finland

Kim HJ, Helfand GE, Howitt RE. 1998. An economic analysis of ozone control in California's San Joaquin Valley. J Agric Resource Econ 23:55-70.

Legge $\mathrm{AH}$, Grunhage $L$, Nosal $M$, et al. 1995. Ambient ozone and adverse crop response: An evaluation of North American and European data as they relate to exposure indices and critical levels. Angew Bot
69:192-205.

Manning WJ, Krupa SV. 1992. Experimental methodology for studying the effects of ozone on crops and trees. In: Lefohn AS (ed.) Surface Level Ozone Exposures and Their Effects on Vegetation. Chelsea, MI: Lewis. p 93-156.

Murphy JJ, Deluki MA, McCubbin DR, et al. 1999. The cost of crop damage caused by ozone air pollution from motor vehicles. J Environ Mgmt 55:273-89.

Mutters R, Soret S. 1998. Statewide potential crop losses from ozone exposure. Final Report to California Air Resources Board on Contract 94-345. www.arb.ca.gov/rd/rd.htm.

Olszyk DM, Bytnerowicz A, Kats G, et al. 1986. Crop effects from air pollutants in air exclusion systems vs. field chambers. J Environ Qual 15:417-22.

Olszyk D, Bytnerowicz A, Kats G, et al. 1993. Cotton yield losses and ambient ozone concentrations in California's San Joaquin Valley. J Environ Qual 22:602-11.

Santos BM, Bewick TA, Stall WM, et al. 1997. Competitive interactions of tomato (Lycopersicon esculentum) and nutsedges (Cyperus spp.). Weed Sci 45:229-33.

Spash CL. 1997. Assessing the economic benefits to agriculture from air pollution control. J Econ Surv 11:47-70.

Temple PJ, Surano KA, Mutters RG, et al. 1985. Air pollution causes moderate damage to tomatoes. Cal Ag 39(3-4):20-2.

Temple PJ, Taylor OC, Benoit LF. 1985. Cotton yield responses to ozone as mediated by soil moisture and evapotranspiration. J Environ Qual 14:1.

Varshney CK, Rout C. 1998. Ethylene diurea (EDU) protection against ozone injury in tomato plants at Delhi. Bull Environ Contam Toxicol 61:188-93. 